\title{
Bilateral pulmonary artery banding for extremely low birth weight infants with coarctation or interruption of the aorta weighing less than $1.0 \mathrm{~kg}$
}

\author{
Yoichi Kawahira, MD, Kyoichi Nishigaki, MD, and Yoshito Maehata, MD, Osaka, Japan
}

Surgical results for coarctation of the aorta $(\mathrm{CoA})$ or interruption of the aorta (IAA) are now excellent, ${ }^{1}$ but the repair may still carry a high risk in extremely preterm neonates. ${ }^{1,2}$ Bilateral pulmonary artery banding (PAB) has been performed as a first palliation for hypoplastic left heart syndrome with a poor preoperative condition. ${ }^{3}$ This procedure also would be useful as a first palliation for extremely small patients with CoA or IAA. We successfully performed bilateral $\mathrm{PAB}$ followed by arch reconstruction and intracardiac repair in 2 extremely low birth weight infants.

\section{CLINICAL SUMMARY Case 1}

A preterm female infant (32 weeks of gestation) was delivered with a birth weight of $886 \mathrm{~g}$. The day after birth, anuria and poor pulsation of the femoral artery were detected with systemic acidosis. Echocardiography showed ventricular septal defect (VSD), CoA with hypoplastic arch, and patent ductus arteriosus; the proximal arch was $2.3 \mathrm{~mm}$, the distal arch was $3.0 \mathrm{~mm}$, and the isthmus was $1.5 \mathrm{~mm}$ in diameter (Figure 1, A). Prostaglandin E1 was administered.

We decided to perform bilateral PAB because of progressive heart failure in this 32-day-old baby weighing $900 \mathrm{~g}$. The operation was carried out through a median sternotomy. The bilateral pulmonary arteries were $4.5 \mathrm{~mm}$ and $4 \mathrm{~mm}$. To perform PAB in this small baby, we first marked a heavy silk suture at exactly $9 \mathrm{~mm}$, and PAB was carried out bilaterally by placing a transfixing suture at the marked position with a 5-0 Prolene suture. The patent ductus arteriosus was left open, and the baby was maintained with prostaglandin E1.

At 4 months of age, the infant's distal arch and descending aorta were increased to $4.5 \mathrm{~mm}$ and $6.5 \mathrm{~mm}$ in diameter, respectively (Figure 1, B). This 2.5 -kg infant received successful arch repair, VSD closure, patent foramen ovale closure, and debanding of both pulmonary arteries. Enlargement of the pulmonary arteries was not needed.

\footnotetext{
From the Department of Pediatric Cardiovascular Surgery, Osaka City General Hospital, Miyakojimaku, Osaka, Japan.

Disclosures: None.

Received for publication April 4, 2009; revisions received June 17, 2009; accepted for publication Aug 9, 2009; available ahead of print Nov 18, 2009.

Address for reprints: Yoichi Kawahira, MD, Departments of Pediatric, Cardiovascular Surgery, Osaka City General Hospital, 2-13-22 Miyakojimahondori, Miyakojimaku,

Osaka, 534-0021, Japan (E-mail: ykawahir@mac.com).

J Thorac Cardiovasc Surg 2010;139:1339-40

$0022-5223 / \$ 36.00$

Copyright $(2010$ by The American Association for Thoracic Surgery

doi: $10.1016 / j$.jtcvs.2009.08.034
}

The infant was extubated on the sixth postoperative day. Echocardiography showed no significant stenosis of both pulmonary arteries and the aortic arch. She is currently doing well.

\section{Case 2}

A preterm female infant (33 weeks of gestation) was delivered with a birth weight of $1066 \mathrm{~g}$. Routine echocardiography showed CoA, small perimembranous VSD, patent foramen ovale, and patent ductus arteriosus, and ductal shock was about to occur with a base excess of -10 . The hypoplastic arch and isthmus were $2.3 \mathrm{~mm}$ and $1.9 \mathrm{~mm}$ in diameter, respectively. Because of heart failure, this 12 day-old baby received bilateral PAB at a body weight of $850 \mathrm{~g}$. Circumference of the tapes was exactly $9 \mathrm{~mm}$ each. Her hemodynamics improved. She was extubated on the sixth postoperative day. Three months later, she weighed $2.4 \mathrm{~kg}$ after receiving successful arch repair and debanding of the pulmonary arteries. Enlargement of the pulmonary arteries was not needed. She was extubated on the seventh postoperative day. Postoperative cardiac angiogram showed no significant stenosis of the bilateral pulmonary arteries and aortic arch.

\section{DISCUSSION}

Small body weight at operation has been reported as a significantly higher mortality risk in arch and intracardiac repair. ${ }^{1,2}$ Bilateral PAB has been induced for hypoplastic left heart syndrome with a poor condition. ${ }^{3,4}$ This procedure would be helpful to control excessive pulmonary blood flow without invasive procedures, such as the Norwood operation. This method could be extended for patients with CoA or IAA associated with excessive pulmonary blood, especially for small patients weighing less than $1 \mathrm{~kg}$.

Although the circumference of PAB for these small patients is unclear, we have successfully carried out bilateral PAB with a circumference of $9 \mathrm{~mm}$. Circumference less than $8 \mathrm{~mm}$ seems to be difficult to exactly control the diameter of the small pulmonary arteries in these babies and be in danger of complete obstruction of the arteries. When patients continue to have excessive pulmonary blood flow after this procedure or cannot be extubated, there may be no other choice but arch and intracardiac repair.

The timing of arch repair and defects closure is also important. As body weight increases with time, the tighter PAB might be for patients. In addition, end-diastolic volume of the left ventricle might decrease. Our patients successfully received arch reconstruction and intracardiac repair at the 


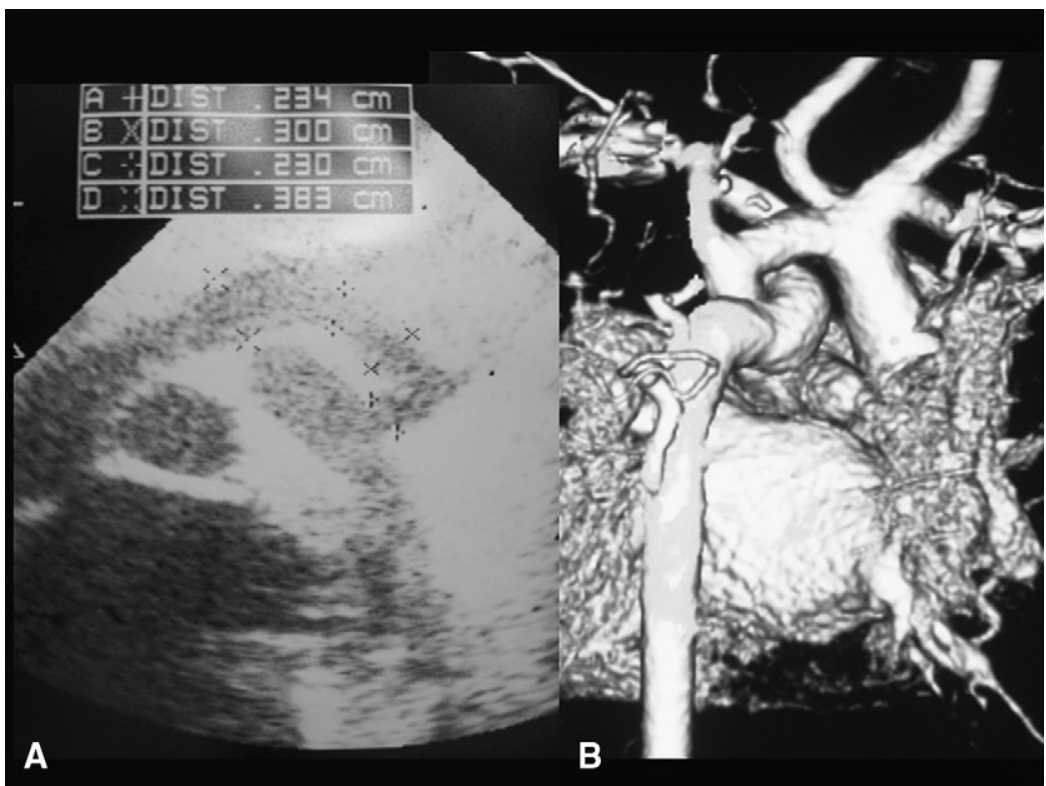

FIGURE 1. Aortic arch before (A) and after (B) bilateral PAB.

age of 3 or 4 months after birth with a body weight of $2.5 \mathrm{~kg}$ and $2.4 \mathrm{~kg}$, respectively. Because both infants did not require plasty of the bilateral pulmonary arteries, this might be an appropriate age for repair.

\section{CONCLUSIONS}

A surgical strategy consisting of bilateral PAB followed by arch and intracardiac repair would be a choice for extremely low birth weight infants with CoA or IAA.

\section{References}

1. Bacha EA, Almodovar M, Wessel DL, et al. Surgery for coarctation of the aorta in infants weighing less than $2 \mathrm{~kg}$. Ann Thorac Surg. 2001;71:1260-4.

2. Curzon CL, Milford-Beland S, Li JS. Cardiac surgery in infants with low birth weight is associated with increased mortality: analysis of the Society of Thoracic Surgeons Congenital Heart Database. J Thorac Cardiovasc Surg. 2008;135: 546-51.

3. Ishizaka T, Ohye RG, Suzuki T, Devaney EJ, Bove EL. Bilateral pulmonary artery banding for resuscitation in hypoplastic left heart syndrome. Ann Thorac Surg. 2003; 75:277-9.

4. Alsoufi B, Bennetts J, Verma S, Caldarone CA. New developments in the treatment of hypoplastic left heart syndrome. Pediatrics. 2007;119:109-17.

\title{
Aortic cusp repair with Gore-Tex sutures during aortic valve-sparing operations
}

\author{
Tirone E. David, MD, and Susan Armstrong, MSc, Toronto, Ontario, Canada
}

Aortic root aneurysms often have normal or near normal aortic cusps, but as the sinotubular junction dilates, the coaptation area of the aortic cusps decreases and the mechanical

From the Division of Cardiovascular Surgery of the Peter Munk Cardiac Centre at Toronto General Hospital and University of Toronto, Ontario, Canada Disclosures: None.

Received for publication Feb 11, 2009; accepted for publication June 10, 2009; available ahead of print July 21, 2009.

Address for reprints: Tirone E. David, MD, 200 Elizabeth St 4N457, Toronto, Ontario M5G2C4, Canada (E-mail: tirone.david@uhn.on.ca).

J Thorac Cardiovasc Surg 2010;139:1340-2

$0022-5223 / \$ 36.00$

Copyright (C) 2010 by The American Association for Thoracic Surgery

doi:10.1016/j.jtcvs.2009.06.010 stress increases; the cusps may become thinner and overstretched, and may develop stress fenestration along the commissures or even become detached from the commissural areas. If the free margin of a cusp is elongated, it will prolapse after correction of the dilation of the sinotubular junction during aortic valve-sparing procedures. In addition, cusps with stress fenestration may rupture late after reconstruction of the aortic root.

Cusp prolapse is usually corrected by plication of its central portion along the nodule of Arantius or by weaving a double layer of a fine polytetrafluoroethylene suture (Gore-Tex; WL Gore and Associates, Flagstaff, Ariz) along the free margin and shortening the free margin. ${ }^{1}$ 